\title{
What Next After Metformin? Thinking Beyond Glycaemia: Are SGLT2 Inhibitors the Answer?
}

\author{
Marc Evans · Angharad R. Morgan · Zaheer Yousef
}

Received: July 11, 2019 / Published online: August 13, 2019

(C) The Author(s) 2019

\section{ABSTRACT}

The prevalence of type 2 diabetes continues to increase, along with a proliferation of glucoselowering treatment options. There is universal agreement in the clinical community for the use of metformin as the first-line glucose-lowering therapy for the majority of patients. However, controversy exists regarding the choice of second-line therapy once metformin is no longer effective. The most recent treatment consensus focuses on the presence of cardiovascular disease, heart failure or kidney disease as a determinant of therapy choice. The majority of patients in routine practice, however, do not fall into such categories. Heart failure and kidney disease represent significant clinical and cost considerations in patients with type 2 diabetes and have a close

Enhanced Digital Features To view enhanced digital features for this article go to https://doi.org/10.6084/ m9.figshare.9170993.

M. Evans ( $\square)$

Diabetes Resource Centre, University Hospital

Llandough, Cardiff, UK

e-mail: marclyndon1@hotmail.com

A. R. Morgan

Health Economics and Outcomes Research Ltd, Cardiff, UK

Z. Yousef

Wales Heart Research Institute, Cardiff University, Cardiff, UK pathophysiological association. Recent data has illustrated that sodium-glucose transporter 2 (SGLT2) inhibitor therapy can reduce the burden of heart failure and the progression of renal disease across a wide range of patients including those with and without established disease, supported by an increased understanding of the mechanistic effects of these agents. Furthermore, there is growing evidence to illustrate the overall safety profile of this class of agents and support the benefit-risk profile of SGLT2 inhibitors as a preferred option following metformin monotherapy failure, with respect to both kidney disease progression and heart failure outcomes.

Keywords: Cardiorenal

disease; Cardiovascular; Chronic kidney disease; Heart failure; Sodium-glucose transporter 2 inhibitor; Type 2 diabetes mellitus

\section{TYPE 2 DIABETES MELLITUS}

Diabetes is a growing global public health concern with patient numbers having quadrupled over the past three decades [1]. It has been estimated that currently approximately 425 million adults (1 in 11) worldwide have diabetes, $90 \%$ of whom have type 2 diabetes mellitus (T2DM) [2, 3]. 
T2DM is a consequence of a reduction in both insulin secretion and insulin sensitivity [4], and results in hyperglycaemia manifesting with a range of symptoms [5]. The majority of patients with T2DM have microvascular (kidney disease, neuropathy, retinopathy) and macrovascular complications [coronary artery disease, myocardial infarction, stroke, congestive heart failure (HF), peripheral vascular disease] which increase mortality [6] and result in a substantial clinical and economic burden [7]. It is estimated that diabetes currently accounts for around $10 \%$ of the total UK National Health Service (NHS) budget, with most of these costs due to the associated complications, as opposed to prescribing costs [8]. For example, the cost of treating cardiovascular disease (CVD) is estimated to comprise $20-49 \%$ of the total T2DM treatment costs [9]. This article is based on previously conducted studies and does not contain any studies with human participants or animals performed by any of the authors.

\section{CURRENT T2DM THERAPEUTIC APPROACH}

In order to achieve normoglycaemia, patients with T2DM are initially managed with lifestyle modifications [10-12]. For many patients whose blood glucose levels cannot be controlled by diet and exercise alone, glucose-lowering medications are required. Metformin is the most widely accepted first-line treatment for T2DM due to its high efficacy in reducing plasma glucose, good safety profile, tolerability and low cost [13]. It also has beneficial effects beyond glycaemic control such as improvements in endothelial dysfunction, haemostasis and oxidative stress, insulin resistance, lipid profiles and fat redistribution [14].

Although there is general agreement for the use of metformin as first-line treatment for almost all patients with T2DM, there is uncertainty regarding the choice of second-line therapy once metformin is no longer effective in achieving recommended glycaemic targets. Various drug treatments have been approved [e.g. sulfonylureas, meglitinides, thiazolidinediones, dipeptidyl peptidase 4 (DPP-4) inhibitors and glucagon-like peptide 1 (GLP-1) receptor agonists]. However, the question of 'what next after metformin?', particularly in the context of the proliferation of therapy options, remains a complex clinical decision.

Sodium-glucose cotransporter 2 (SGLT2) inhibitors are the newest class of oral anti-hyperglycaemic agents for the treatment of T2DM, and have demonstrated robust efficacy results for glycaemia, blood pressure, haemodynamic outcomes, weight loss and albuminuria [15-22]. On the basis of this efficacy data, the National Institute for Health and Care Excellence (NICE) and the Scottish Intercollegiate Guideline Network (SIGN) recommend that treatment with SGLT2 inhibitors should be considered alongside other glucose-lowering medicines in patients with T2DM who have been unable to achieve glycaemic control with metformin, or as a first-line treatment in cases of metformin intolerance [23, 24].

A major area of uncertainty is whether SGLT2 inhibitors can also be used safely and effectively across the spectrum of cardiorenal disease, including for example patients with T2DM and HF or chronic kidney disease (CKD). A recent consensus report by the American Diabetes Association (ADA) and the European Association for the Study of Diabetes (EASD) [25] considers outcomes beyond glycaemic control [25]. Post-metformin the report recommends SGLT2 inhibitors (or GLP-1 receptor agonists with proven $\mathrm{CV}$ benefit) for patients with T2DM who have established atherosclerotic CVD; SGLT2 inhibitors for patients with atherosclerotic CVD in whom HF coexists or is of special concern; and SGLT2 inhibitors (or GLP-1 receptor agonists shown to reduce CKD progression) for patients with T2DM and CKD, with or without CVD.

Even though glycaemic control remains the main focus for T2DM treatments, given the clinical burden that $\mathrm{HF}$ and CKD have on patients with T2DM, it is important that treatment approaches consider the joint management of T2DM and cardiorenal disease. As such, the major change in the ADA/EASD recommendations compared to previous guidelines is based on new evidence that SGLT2 inhibitors improve $\mathrm{CV}$ outcomes, as well as secondary 
outcomes such as HF and progression of renal disease, in patients with established CVD or CKD. This approach is further supported by the recently published results of the DECLARE-TIMI 58 study [17] in which the effects of dapagliflozin, compared to standard of care, on CV, HF and renal outcomes were assessed in patients with and without established CVD. The results imply that the HF and renal outcome benefits of SGLT2 inhibitors observed in patients with established disease also extend to lower-risk patients.

\section{HEART FAILURE AND KIDNEY DISEASE IN T2DM}

\section{Heart Failure}

Traditionally, concerns around CV outcomes in patients with T2DM have focused on the endpoints of the atherosclerotic disease process, such as myocardial infarction, stroke, and limb ischemia. However, one of the most common and serious initial manifestations of CVD in T2DM is $\mathrm{HF}$, accounting for $14 \%$ of CV events [26], and estimated to affect more than $22 \%$ of patients with T2DM in primary care [27]. HF is of particular concern in the diabetic population since the diabetic substrate is a major risk factor for both HF with reduced ejection fraction (HFREF) and HF with preserved ejection fraction (HFPEF).

HF prognosis is worse in patients with diabetes than in patients without diabetes [28], and despite advances in care, HF patients continue to have worse survival (approximately 50\% mortality at 5 years after initial diagnosis) than patients with some of the most common cancers $[29,30]$. HF hospitalisation $(\mathrm{HFH})$ is a marker for significant adverse prognosis with high in-hospital and post-discharge mortality as well as significant repeat HFH rates [31-33], which often worsen clinical outcomes further [34]. Moreover, hospitalisation stays are expensive for healthcare providers and account for the majority $(60 \%)$ of the costs associated with HF management [35]. Thus, HFH prevention represents an important therapeutic goal to alleviate both the clinical and economic burden of T2DM.

\section{Kidney Disease}

Kidney disease is one of the most common complications of T2DM. Approximately $30-40 \%$ of patients with T2DM also have CKD $[36,37]$, defined as estimated glomerular filtration rate $(\mathrm{eGFR}) \leq 60 \mathrm{ml} / \mathrm{min} / 1.73 \mathrm{~m}^{2}$ and/or urinary albumin/creatinine ratio $\geq 30 \mathrm{mg} / \mathrm{g}$ [38]. These patients are at increased risk of premature mortality, CV morbidity and end-stage renal disease (ESRD) [39]. Five-year survival for patients with ESRD is less than 40\% [37]. Furthermore, healthcare costs for CKD patients are high: T2DM with CKD has been associated with mean annual costs 49\% higher than T2DM without CKD [40]. There is a particular inflection point with respect to disease burden and cost with progression from CKD stage $3 \mathrm{a}$ to $3 \mathrm{~b}$ (reduction in eGFR $<45 \mathrm{ml} / \mathrm{min} / 1.73 \mathrm{~m}^{2}$ ) [41] (Fig. 1). Delaying progression of kidney disease, on both an individual and population level, is likely to be rewarded by significant health and cost benefits. To date, approaches to delay the progression of renal disease in patients with T2DM have focused on multiple risk factor control along with inhibition of the renin-angiotensin system [42].

\section{The Cardiorenal Syndrome}

Many of the risk factors thought to promote CVD in T2DM (e.g. hypertension, dyslipidaemia and obesity) are also common in CKD. Additionally, there is a close physiological relationship in mechanistic terms between $\mathrm{HF}$ and kidney disease: the cardiorenal syndrome (Fig. 2). This process is bidirectional between the heart and kidneys with dysfunction in one organ promoting dysfunction in the other organ, and involves many different processes including sympathetic nervous system activation, increased venous pressure, renin-angiotensin system activation, vasoconstriction, sodium and water retention [43]. Any intervention in patients with T2DM that could address the natural history of HF and kidney disease would have considerable value from clinical, economic and physiological perspectives. 


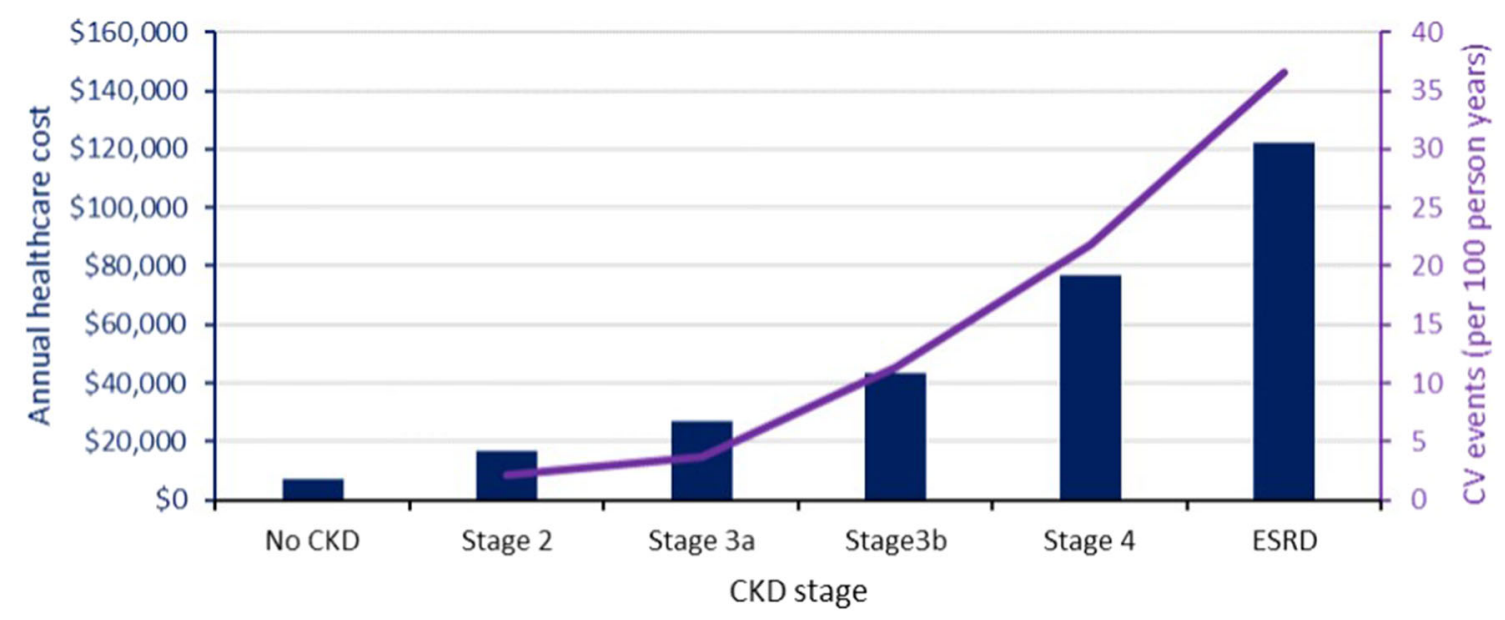

Fig. 1 Increasing disease burden and cost with CKD progression. There is an increase in adverse outcomes $(\mathrm{CV}$ (USD) with CKD progression. CKD chronic kidney events per 100 person years) and annual healthcare costs disease, $\mathrm{CV}$ cardiovascular

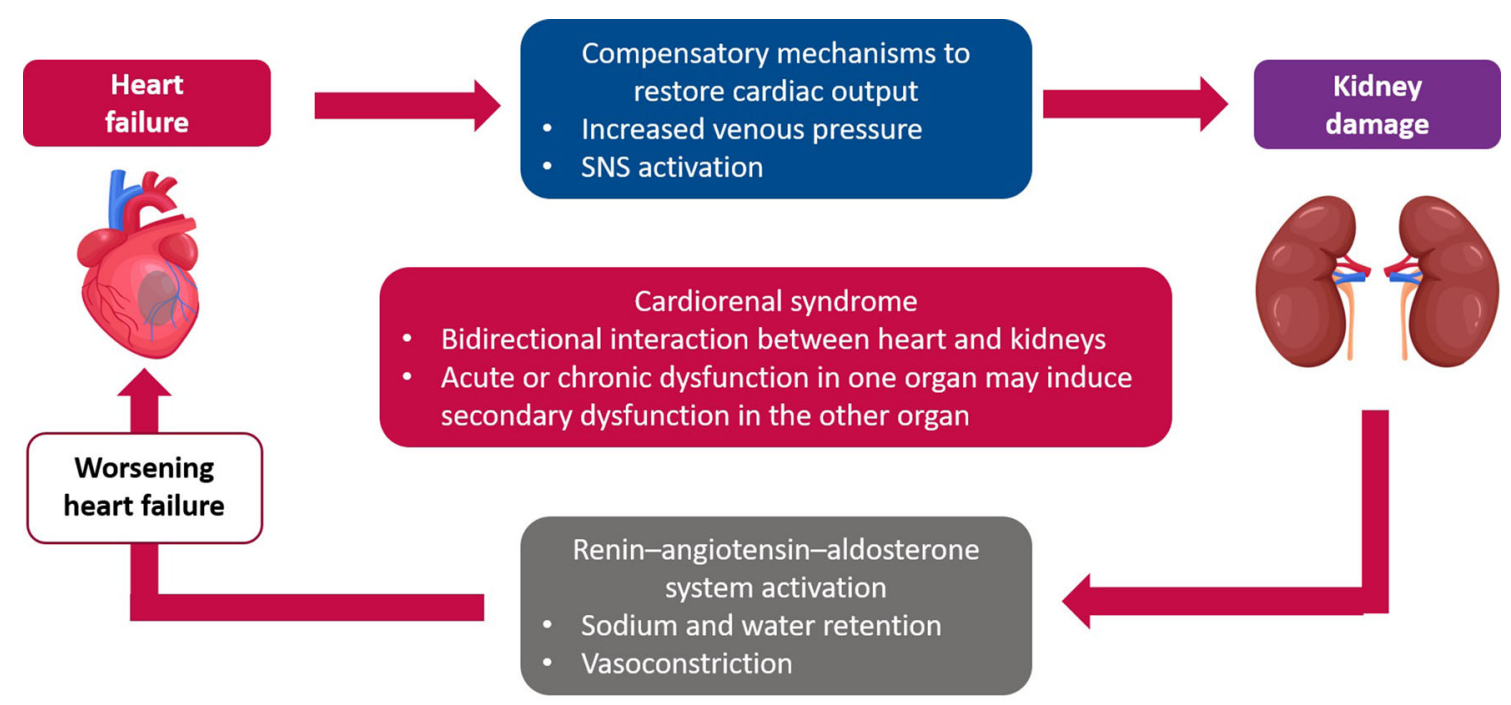

Fig. 2 The link between heart failure and kidney disease in type 2 diabetes

\section{THE POTENTIAL OF SGLT2 INHIBITORS AS TREATMENT FOR PATIENTS WITH T2DM AND HF OR CKD}

SGLT2 inhibitors are a relatively new class of treatment that improve glycaemic control in patients with T2DM by decreasing renal glucose reabsorption and increasing urinary glucose excretion [44]. In addition to glycaemic effects,
SGLT2 inhibitors are increasingly recognised to exert significant cardiorenal outcome benefits.

\section{SGLT2 Inhibitor Cardiovascular Outcome Trials}

Previously, two SGLT2 inhibitor cardiovascular outcome trials (CVOTs) have shown a reduction in the risk of major adverse $\mathrm{CV}$ events (MACE) in patients with T2DM and established CVD or at high CV risk: the EMPA-REG OUTCOME trial 
with empagliflozin (ClinicalTrials.gov identifier NCT01131676) [15] and the CANVAS program with canagliflozin (ClinicalTrials.gov identifier NCT01032629) [16]. These studies also showed reductions in the risk of $\mathrm{CV}$ death with empagliflozin and the risk of HFH with both empagliflozin and canagliflozin. The results of these CVOTs are mainly relevant for the prevention of recurrent $\mathrm{CV}$ events rather than the prevention of new CV events as EMPA-REG OUTCOME enrolled only patients with established CVD, and in CANVAS, the reduction in the risk of $\mathrm{CV}$ events was considerably less for patients without prior $\mathrm{CV}$ events than in the overall population or those with prior $\mathrm{CV}$ events.

In contrast to EMPA-REG OUTCOME and CANVAS, the CREDENCE study (ClinicalTrials.gov identifier NCT02065791) was designed to specifically assess effects on clinically important outcomes in patients with T2DM at high risk of kidney disease progression [45]. The study evaluated the efficacy and safety of canagliflozin versus placebo, when used in addition to standard of care. All study patients had an eGFR of 30 to $<90 \mathrm{ml} / \mathrm{min} / 1.73 \mathrm{~m}^{2}$ and albuminuria (urinary albumin/creatinine ratio $>300$ to $5000 \mathrm{mg} / \mathrm{g}$ ) and were treated with renin-angiotensin system blockade. Patients receiving canagliflozin had a 30\% reduction in the risk of the primary composite endpoint, comprising progression to ESRD, doubling of serum creatinine, and renal or CV death, compared to patients in the placebo group. There was also a reduced risk of the secondary $\mathrm{CV}$ endpoints, including the risk of $\mathrm{CV}$ death and HFH by $31 \%$, MACE by $20 \%$ and the risk of $\mathrm{HFH}$ alone by $39 \%$.

The patients included in published studies such as EMPA-REG [15], CANVAS [16] and CREDENCE [45], as well as patients in the VERITS CV study (ClinicalTrials.gov identifier NCT01986881), which is assessing ertugliflozin in patients with T2DM and vascular disease and with results expected later this year [46], are not particularly representative of the general population of patients with T2DM, as most patients with T2DM (67.8\%) do not have established CVD [47]. Since most CVOTs tend to focus on the highest-risk patient population, predominantly with established disease, there is relatively little data available to inform optimal treatment approaches in lower-risk individuals. The only evidence to date is from DECLARETIMI 58 (ClinicalTrials.gov identifier NCT01730534), a multicentre trial to evaluate the effect of dapagliflozin on the incidence of CV events in patients with T2DM [17]. This study included the largest numbers of patients with T2DM at lower CV risk among all CVOTs to date, a population that has not been previously studied with enough patients to be certain of the effects of SGLT2 inhibitors in this population. The patients in the DECLARE-TIMI 58 trial also had better baseline renal function with a low proportion of patients with severe CKD. Table 1 provides a summary of the similarities and differences between the SGLT2 inhibitorbased CVOTs.

The DECLARE-TIMI 58 trial population included 17,160 patients and consisted of patients that were at least 40 years old with established atherosclerotic CVD (ischemic heart disease, peripheral artery disease or cerebrovascular disease $(N=6974,40.6 \%)$ or patients with multiple (two or more) risk factors (at least 55 years old for men and at least 60 years old for women plus at least one of the following: dyslipidaemia, hypertension or current smoking) $(N=10,186,59.4 \%)$. The study examined two primary efficacy endpoints: time to first event of the composite of MACE (CV death, MI, stroke) and the composite of CV death or HFH. Secondary endpoints included time to first event of renal composite endpoint (at least 40\% decrease in eGFR, ESRD, renal death, CV death) and time to all-cause mortality.

With regards to MACE, there was a reduction with dapagliflozin in patients with T2DM and established CVD only. However, the results demonstrated prevention of CV events, particularly HFH, consistently across a broad range of patients with T2DM, regardless of history of existing CVD or HF. The majority of patients (90\%) did not have a history of HF, thus the prevention of future HF is noteworthy. In this population with low CV risk, patients treated with dapagliflozin had a significant reduction of HFH/CV death events: 417 events compared to 496 for those treated with placebo [hazard ratio (HR) 0.83 ; 95\% confidence interval (CI) 0.73, 
Table 1 Comparison of CVOTs

\begin{tabular}{|c|c|c|c|c|c|}
\hline & $\begin{array}{l}\text { EMPA-REG } \\
\text { outcome [15] }\end{array}$ & $\begin{array}{l}\text { CANVAS } \\
\text { program [16] }\end{array}$ & CREDENCE [45] & $\begin{array}{l}\text { VERTIS CV } \\
\text { [46] }\end{array}$ & $\begin{array}{l}\text { DECLARE- } \\
\text { TIMI } 58 \text { [17] }\end{array}$ \\
\hline SGLT2 inhibitor & Empagliflozin & Canagliflozin & Canagliflozin & Ertugliflozin & Dapagliflozin \\
\hline $\begin{array}{c}\text { Number of } \\
\text { patients }\end{array}$ & 7020 & 10,142 & 4401 & 8238 & 17,160 \\
\hline Mean age (years) & $63.1(8.6)$ & $63.3(8.3)$ & $63.0(9.2)$ & $64.4(8.1)$ & $63.8(6.8)$ \\
\hline Male (\%) & 71.2 & 64.2 & 66.1 & 70.0 & 62.6 \\
\hline $\begin{array}{l}\text { Key inclusion } \\
\text { criteria }\end{array}$ & $\begin{array}{l}\mathrm{HbAlc} \geq 7 \% \\
\text { and } \leq 10 \% \\
\mathrm{eGFR}^{\mathrm{a}} \geq 30 \mathrm{ml} / \\
\min / 1.73 \mathrm{~m}^{2}\end{array}$ & $\begin{array}{l}\mathrm{HbAlc} \geq 7 \% \\
\text { and } \leq 10.5 \% \\
\mathrm{eGFR}^{\mathrm{a}}>30 \mathrm{ml} / \\
\mathrm{min} / 1.73 \mathrm{~m}^{2}\end{array}$ & $\begin{array}{l}\mathrm{HbAlc} \geq 6.5 \% \text { and } \\
\leq 12 \% \\
\mathrm{eGFR}^{\mathrm{a}}>30 \text { and } \\
\quad<90 \mathrm{ml} / \mathrm{min} / \\
1.73 \mathrm{~m}^{2}\end{array}$ & $\begin{array}{l}\mathrm{HbAlc} \geq 7 \% \\
\text { and } \leq 10.5 \%\end{array}$ & $\begin{array}{l}\mathrm{HbAlc} \geq 6.5 \% \\
\text { and }<12 \% \\
\mathrm{CrCl}^{\mathrm{a}} \geq 60 \mathrm{ml} / \\
\quad \min \end{array}$ \\
\hline $\begin{array}{l}\text { Median follow-up } \\
\text { (years) }\end{array}$ & 3.1 & 5.7 & 2.6 & TBD & 4.5 \\
\hline CVD (\%) & 100 & 65.6 & 50.4 & 99.9 & 40.6 \\
\hline $\begin{array}{c}\text { Mean eGFR }(\mathrm{ml} / \\
\left.\min / 1.73 \mathrm{~m}^{2}\right)\end{array}$ & $74.1(21)$ & $76.5(20.5)$ & $56.2(18.2)$ & $76.0(20.9)$ & $86.1(21.8)$ \\
\hline $\begin{array}{l}\text { History of HF } \\
(\%)\end{array}$ & 10.1 & 14.4 & 14.8 & 23.1 & 10.0 \\
\hline
\end{tabular}

Numbers between parentheses are standard deviations

$C V D$ cardiovascular disease, $C r C l$ creatinine clearance, $e G F R$ estimated glomerular filtration rate, SGLT2 sodium-glucose transporter 2, TBD to be determined

a Glomerular filtration rate (GFR) describes the flow rate of filtered fluid through the kidney. Creatinine clearance rate $(\mathrm{CCr}$ or $\mathrm{CrCl})$ is the volume of blood plasma that is cleared of creatinine per unit time and is a useful measure for approximating the GFR

$0.95 ; p=0.005]$. This result was driven by the HFH outcome: there were $212 \mathrm{HFH}$ events in the dapagliflozin group compared to 286 in the placebo group (HR 0.73; 95\% CI 0.61, 0.88). With regards to $\mathrm{CV}$ death there were 245 events in the dapagliflozin group compared to 286 in the placebo group (HR 0.98; 95\% CI 0.82, 1.17).

The results from the DECLARE-TIMI 58 trial also demonstrated reduced renal disease progression in patients with T2DM treated with the SGLT2 inhibitor, most of whom had normal renal function. Patients in the dapagliflozin group had fewer renal events [renal composite endpoint defined as eGFR decrease $\geq 40 \%$ to eGFR $<60 \mathrm{ml} / \mathrm{min} / 1.73 \mathrm{~m}^{2}$ and/or ESRD (dialysis $\geq 90$ days, kidney transplantation or eGFR $<15 \mathrm{ml} / \mathrm{min} / 1.73 \mathrm{~m}^{2}$ ) and/or renal or CV death] compared to those in the placebo group; 370 events compared to 480 (HR 0.76; 95\% CI $0.67,0.87 ; p<0.001)$. Excluding death from $\mathrm{CV}$ causes, the HR for the renal-specific outcome was 0.53 (95\% CI $0.43,0.66$; $p<0.0001)$. Individual components of the renal composite outcomes were also significantly reduced with dapagliflozin compared to placebo: patients in the dapagliflozin group had lower event rates for an eGFR decline of at least $40 \%$ below the $60 \mathrm{ml} / \mathrm{min} / 1.73 \mathrm{~m}^{2}$ threshold (HR 0.54; 95\% CI $0.43,0.67 ; p<0.001)$ and for ESRD or renal death (HR 0.41; 95\% CI 0.20, 0.82; $p=0.012$ ) compared with the placebo group [48]. The renal benefits associated with dapagliflozin were demonstrated across eGFR subgroups and in both patients with and without established 
CVD highlighting the value of SGLT2 inhibitors for both prevention and treatment of CKD among patients with T2DM.

The cardio- and renoprotective results observed in the DECLARE-TIMI 58 clinical trial have been externally validated in a real-word setting. In a nationwide observational study, using a Swedish population with T2DM $(N=28,408)$ similar to those included in the DECLARE-TIMI 58 study, dapagliflozin resulted in lower event rates of HFH and CV mortality compared to other glucose-lowering drugs: HR 0.79 95\% CI $0.67-0.93$ and HR 0.75 95\% CI $0.57-0.97$, respectively [49].

A meta-analysis of the EMPA-REG OUTCOME, CANVAS and DECLARE-TIMI 58 trials with a total of 34,322 patients $(60.2 \%$ with established atherosclerotic CVD and $39.8 \%$ with multiple risk factors but no known atherosclerotic CVD) further supports the role of SGLT2 inhibitors in reducing the risk of HFH (HR 0.69; 95\% CI $0.61-0.79$ ) and progression of renal disease (HR 0.55; 95\% CI 0.48, 0.64), with results of similar magnitude regardless of the presence of established CVD [50].

\section{SGLT2 Inhibitor Cardiorenal Protection Mechanisms}

The mechanisms of $\mathrm{CV}$ and renal protection observed in the SGLT2 inhibitor CVOTs are yet to be fully elucidated. They are likely to be multifactorial and include effects such as osmotic diuresis and natriuresis (leading to reductions in plasma volume, interstitial fluid, blood pressure and arterial stiffness) and metabolic responses (leading to increases in glucosuria and reductions in HbA1c, glucotoxicity, weight gain, adiposity, inflammation and vascular dysfunction). Improved cardiac fuel energetics may be of particular relevance with respect to the observed effects on both renal and HF outcomes [51, 52] (Fig. 3). More mechanistic studies are, however, required to better understand the role of SGLT2 inhibition with respect to cardiorenal protection.

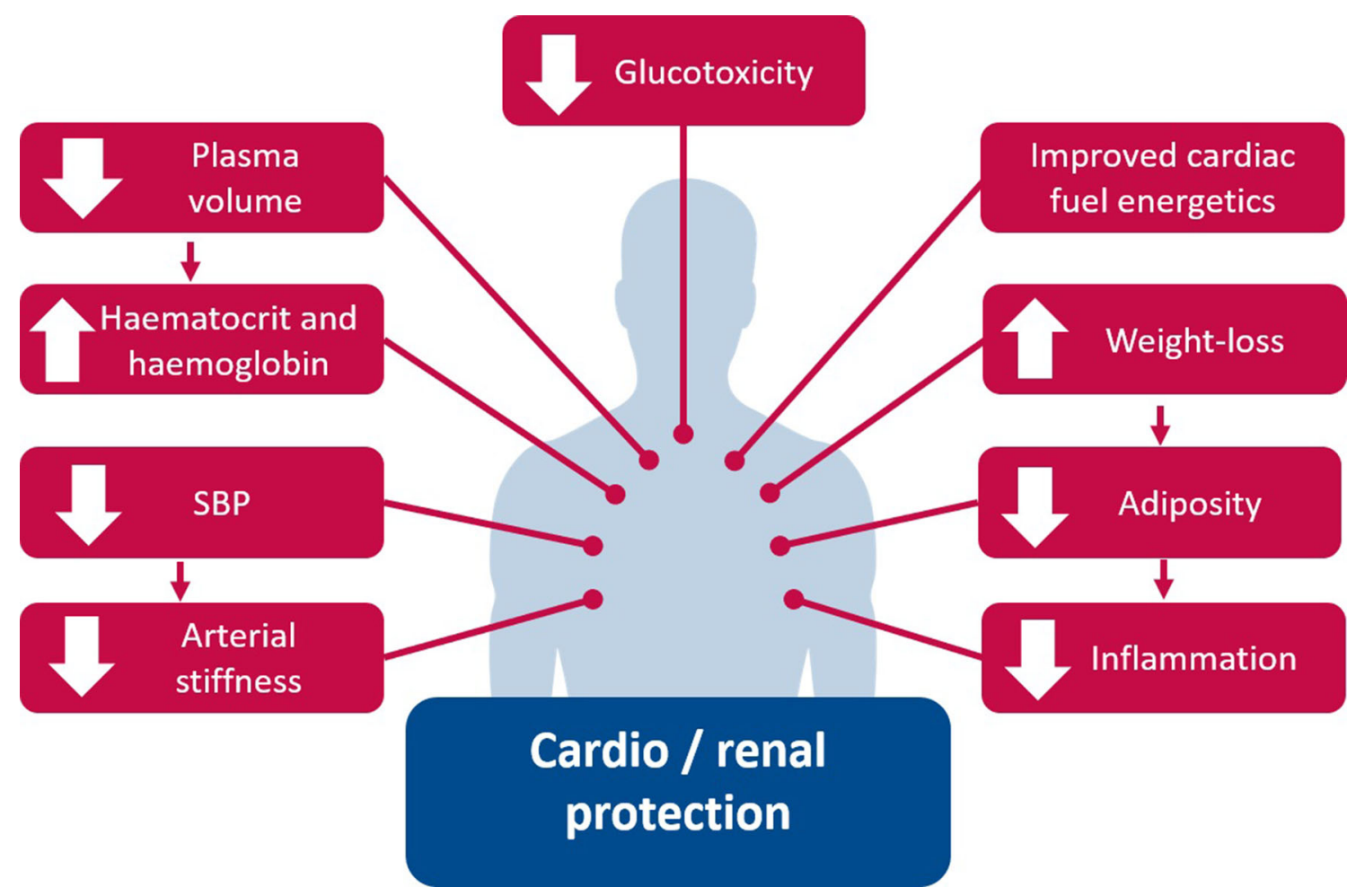

Fig. 3 SGLT2 inhibitor cardiorenal protection mechanistic overview. SBP systolic blood pressure 


\section{Cost-Effectiveness of SGLT2 Inhibitors}

With regards to the cost-effectiveness of the SGLT2 inhibitors, compared to other oral antidiabetes therapies and insulin, for the treatment of individuals with uncontrolled T2DM, a recent systematic review that included 37 pharmacoeconomic studies (15 dapagliflozin; 10 canagliflozin; 12 empagliflozin) demonstrated SGLT2 inhibitors to be the most costeffective option [53]. However, the cost-effectiveness was generally thought to be as a consequence of reduction in HbA1c. Furthermore, there is limited cost-effectiveness evidence aligned to SGLT2 inhibitor CVOTs. There have been two economic analyses, both utilising EMPA-REG [54, 55]. As described above the EMPA-REG study recruited patients with established CV disease only, thereby limiting the generalisability of these cost-effectiveness results to a wider population with T2DM.

\section{SUMMARY: WHAT NEXT AFTER METFORMIN? ARE SGLT2 INHIBITORS THE ANSWER?}

HF and CKD in patients with T2DM represent a significant clinical and economic burden. Current treatment strategies for these patients are based on established disease. Preventing HFH events or renal disease progression even before disease develops remains a large unmet need and important consideration when escalating therapy following metformin failure.

DECLARE-TIMI 58 is the broadest, largest and longest SGLT2 inhibitor CVOT to date, with the largest proportion and numbers of patients with T2DM at lower risk. In this population, dapagliflozin was found to be both cardio- and renoprotective: dapagliflozin-treated patients had fewer MACE events and a significant reduction of $\mathrm{HFH} / \mathrm{CV}$ death and dapagliflozin also slowed renal disease progression in patients with T2DM and relatively preserved baseline renal function. The results of this study demonstrate that using SGLT2 inhibitors in T2DM not only improves glycaemic control, for which these drugs are currently indicated [56-58], but also reduces HFH and delays renal disease progression in both patients with and without existing CVD. Many of the current T2DM guidelines prioritize the use of SGLT2 inhibitors in patients with T2DM and established atherosclerotic vascular disease, HF or CKD. However, with the disease burden of HF and CKD, the results of studies such as DECLARE-TIMI 58 provide persuasive evidence that SGLT2 inhibitor therapy may influence the natural history of these complications across the spectrum of T2DM, with the potential to translate into both clinical benefits and health cost savings. Consequently, treatment with an SGLT2 inhibitor may be considered the most appealing option following metformin monotherapy failure.

There are of course many caveats to such a statement, most notably the absence of any direct comparative studies between agents and between drug classes in this indication, with respect to both clinical and economic outcomes. A pragmatic, unmasked clinical trial, aiming to compare commonly used diabetes medications, when combined with metformin, on glycaemia-lowering effectiveness and patient-centred outcomes is in progress (GRADE. ClinicalTrials.gov identifier NCT01794143) [59]. Medications representing four classes (sulfonylureas, DPP-4 inhibitors, GLP-1 receptor agonists and insulin) will be randomly assigned and added to metformin (minimum-maximum 1000-2000 mg/day); there is no SGLT2 inhibitor comparison. The results of this study will add further fuel to the debate of 'what next after metformin?' since the primary metabolic outcome is the time to primary failure defined as an $\mathrm{HbA} 1 \mathrm{c} \geq 7 \%$ (53 $\mathrm{mmol} / \mathrm{mol})$, subsequently confirmed over an anticipated mean observation period of 4.8 years (range $4-7$ years). Other long-term metabolic outcomes include the need for the addition of basal insulin after a confirmed $\mathrm{HbA} 1 \mathrm{c}>7.5 \%(58 \mathrm{mmol} / \mathrm{mol})$, and ultimately the need to implement an intensive basal/bolus insulin regimen. The four drugs will also be compared with respect to selected microvascular complications, CVD risk factors, adverse effects, tolerability, quality of life and cost-effectiveness. Furthermore, from a mechanistic 
perspective, in terms of both $\mathrm{CV}$ and renal outcomes, the optimal approach may include a combination of GLP-1 receptor agonists with $\mathrm{CV}$ outcome benefits such as semaglutide, liraglutide or dulaglutide, with an SGLT2 inhibitor. Indeed, considering the observed outcome benefits in studies such as LEADER [60, 61], SUSTAIN 6 [62] and REWIND [63, 64] alongside those observed in the SGLT2 inhibitor CVOTs implies potential for complementary outcome benefits in terms of atherosclerotic disease, HF and renal disease progression.

If we are to advocate the use of a relatively new therapeutic entity such as an SGLT2 inhibitor as widely as the preferred treatment option following metformin failure, then safety is an extremely important consideration. Some concerns have been raised regarding the safety of SGLT2 inhibitors, particularly adverse events including mycotic genital infections, Fournier gangrene, diabetic ketoacidosis (DKA), acute kidney injury, lower-limb amputation and fracture [15-17, 65-68]. There has been considerable focus on the safe and optimal use of the SGLT2 inhibitors in clinical practice [69]. Data from the DECLARE-TIMI 58 study further supports the safety profile of the SGLT2 inhibitors. Dapagliflozin was not associated with any excess in amputation, bone fracture, urinary tract infection, malignancy, Fournier gangrene, volume depletion or hypoglycaemia compared with placebo, and there were numerically fewer cases of acute kidney injury with dapagliflozin (1.5\% vs. $2.0 \%)$. Genital mycotic infections and adjudicated DKA were both higher in dapagliflozin-treated subjects $(0.9 \%$ vs. $0.1 \%$ and $0.3 \%$ vs. $0.1 \%$, respectively); however, these adverse events occurred at a very low frequency and as such the benefit-risk profile remains overwhelmingly in favour of the SGLT2 inhibitor. The risk of adverse events should not mask the $\mathrm{CV}$ and renal benefits of SGLT2 inhibitors as results from the majority of studies indicate that the safety profile of SGLT2 inhibitors is good. However, SGLT2 inhibitor clinical studies have been of relatively short duration, with DECLARE-TIMI 58 having the longest median follow-up of over 4 years [17]. As such, further studies assessing both efficacy and safety of
SGLT2 inhibitors in longer-term trials are now needed.

Any widespread therapy implementation should ideally be supported by robust mechanistic data. The mechanisms of action of SGLT2 inhibitors that drive the observed cardiorenal benefits are yet to be fully determined but are likely to include systemic and metabolic effects [70-73]. Mechanistic clinical trials such as DapaMech [74] are currently being undertaken in patients with HF and CKD, both with and without T2DM, to advance our understanding of the underlying science behind the $\mathrm{CV}$ and renal effects of SGLT2 inhibitors.

On the basis of current data, SGLT2 inhibitors certainly appear a very attractive option following metformin monotherapy failure. Further clinical research and real-world studies investigating SGLT2 inhibitors across the spectrum of patients with T2DM are, however, needed to fully define both the clinical and economic value of SGLT2 inhibitors following metformin monotherapy failure.

\section{ACKNOWLEDGEMENTS}

Funding. No funding or sponsorship was received for this study or publication of this article.

Authorship. All named authors meet the International Committee of Medical Journal Editors (ICMJE) criteria for authorship for this article, take responsibility for the integrity of the work as a whole, and have given their approval for this version to be published.

Disclosures. Marc Evans has received research awards and honoraria from Novo Nordisk, AstraZeneca, Takeda, Novartis, BI and Sunovion and is the Editor-in-Chief of the journal. Zaheer Yousef has received honoraria from AstraZeneca and BI. Angharad R. Morgan has nothing to disclose.

Compliance with Ethics Guidelines. This article is based on previously conducted studies and does not contain any studies with human 
participants or animals performed by any of the authors.

Data Availability. Data sharing is not applicable to this article as no datasets were generated or analysed during the current study.

Open Access. This article is distributed under the terms of the Creative Commons Attribution-NonCommercial 4.0 International License (http://creativecommons.org/licenses/ by-nc/4.0/), which permits any noncommercial use, distribution, and reproduction in any medium, provided you give appropriate credit to the original author(s) and the source, provide a link to the Creative Commons license, and indicate if changes were made.

\section{REFERENCES}

1. Zheng Y, Ley SH, Hu FB. Global aetiology and epidemiology of type 2 diabetes mellitus and its complications. Nat Rev Endocrinol. 2018;14(2):88-98. https://doi.org/10.1038/nrendo.2017.151.

2. International Diabetes Federation. IDF diabetes atlas-8th edition. 2017. https://www.diabetesatlas. org/. Accessed 1 July 2019.

3. Scully $T$. Diabetes in numbers. Nature. 2012;485(7398):S2-3.

4. Guillausseau PJ, Meas T, Virally M, Laloi-Michelin M, Medeau V, Kevorkian JP. Abnormalities in insulin secretion in type 2 diabetes mellitus. Diabetes Metab. 2008;34(Suppl 2):S43-8. https://doi. org/10.1016/s1262-3636(08)73394-9.

5. Medscape. Type 2 diabetes mellitus. 2019. https:// emedicine.medscape.com/article/117853-overview. Accessed 1 July 2019.

6. Cusick M, Meleth AD, Agron E, et al. Associations of mortality and diabetes complications in patients with type 1 and type 2 diabetes: early treatment diabetic retinopathy study report no. 27. Diabetes Care. 2005;28(3):617-25. https://doi.org/10.2337/ diacare.28.3.617.

7. Mohammedi K, Woodward M, Marre M, et al. Comparative effects of microvascular and macrovascular disease on the risk of major outcomes in patients with type 2 diabetes. Cardiovasc Diabetol. 2017;16(1):95. https://doi.org/10.1186/ s12933-017-0574-y.
8. Hex N, Bartlett C, Wright D, Taylor M, Varley D. Estimating the current and future costs of type 1 and type 2 diabetes in the UK, including direct health costs and indirect societal and productivity costs. Diabet Med. 2012;29(7):855-62. https://doi. org/10.1111/j.1464-5491.2012.03698.x.

9. Einarson TR, Acs A, Ludwig C, Panton UH. Economic burden of cardiovascular disease in type 2 diabetes: a systematic review. Value Health. 2018;21(7):881-90. https://doi.org/10.1016/j.jval. 2017.12.019.

10. Bantle JP, Wylie-Rosett J, Albright AL, et al. Nutrition recommendations and interventions for diabetes-2006: a position statement of the American Diabetes Association. Diabetes Care. 2006;29(9):2140-57..

11. Schellenberg ES, Dryden DM, Vandermeer B, Ha C, Korownyk C. Lifestyle interventions for patients with and at risk for type 2 diabetes: a systematic review and meta-analysis. Ann Intern Med. 2013;159(8):543-51. https://doi.org/10.7326/00034819-159-8-201310150-00007.

12. Hu FB, Manson JE, Stampfer MJ, et al. Diet, lifestyle, and the risk of type 2 diabetes mellitus in women. N Engl J Med. 2001;345(11):790-7. https://doi.org/ 10.1056/nejmoa010492.

13. Rojas LB, Gomes MB. Metformin: an old but still the best treatment for type 2 diabetes. Diabetol Metab Syndr. 2013;5(1):6. https://doi.org/10.1186/ 1758-5996-5-6.

14. Scarpello JH, Howlett HC. Metformin therapy and clinical uses. Diabetes Vasc Dis Res. 2008;5(3):157-67. https://doi.org/10.3132/dvdr. 2008.027.

15. Zinman B, Wanner C, Lachin JM, et al. Empagliflozin, cardiovascular outcomes, and mortality in type 2 diabetes. $\mathrm{N}$ Engl J Med. 2015;373(22):2117-28. https://doi.org/10.1056/ nejmoa1504720.

16. Neal B, Perkovic V, Mahaffey KW, et al. Canagliflozin and cardiovascular and renal events in type 2 diabetes. N Engl J Med. 2017;377(7):644-57. https://doi.org/10.1056/nejmoa1611925.

17. Wiviott SD, Raz I, Bonaca MP, et al. Dapagliflozin and cardiovascular outcomes in type 2 diabetes. N Engl J Med. 2019;380(4):347-57. https://doi.org/ $10.1056 /$ nejmoa1812389.

18. Neeland IJ, McGuire DK, Chilton R, et al. Empagliflozin reduces body weight and indices of adipose distribution in patients with type 2 diabetes mellitus. Diabetes Vasc Dis Res. 2016;13(2):119-26. https://doi.org/10.1177/1479164115616901. 
19. Bolinder J, Ljunggren O, Kullberg J, et al. Effects of dapagliflozin on body weight, total fat mass, and regional adipose tissue distribution in patients with type 2 diabetes mellitus with inadequate glycemic control on metformin. J Clin Endocrinol Metab. 2012;97(3):1020-31. https://doi.org/10.1210/jc. 2011-2260.

20. Fitchett D, Butler J, van de Borne P, et al. Effects of empagliflozin on risk for cardiovascular death and heart failure hospitalization across the spectrum of heart failure risk in the EMPA-REG OUTCOME® trial. Eur Heart J. 2018;39(5):363-70. https://doi. org/10.1093/eurheartj/ehx511.

21. Verma S, Mazer CD, Al-Omran M, et al. Cardiovascular outcomes and safety of empagliflozin in patients with type 2 diabetes mellitus and peripheral artery disease: a subanalysis of EMPA-REG OUTCOME. Circulation. 2018;137(4):405-7. https://doi.org/10.1161/circulationaha.117. 032031.

22. Kosiborod M, Cavender MA, Fu AZ, et al. Lower risk of heart failure and death in patients initiated on sodium-glucose cotransporter-2 inhibitors versus other glucose-lowering drugs: the CVD-REAL study (Comparative Effectiveness of Cardiovascular Outcomes in New Users of Sodium-Glucose Cotransporter-2 Inhibitors). Circulation. 2017;136(3):249-59. https://doi.org/10.1161/ circulationaha.117.029190.

23. National Institute for Health and Care Excellence. NICE guideline [NG28]: type 2 diabetes in adults: management. 2017. https://www.nice.org.uk/ guidance/ng28. Accessed 1 July 2019.

24. Scottish Intercollegiate Guideline Network. SIGN 154: pharmacological management of glycaemic control in people with type 2 diabetes. 2017. https://www.sign.ac.uk/assets/sign154.pdf. Accessed 1 July 2019.

25. Davies MJ, D'Alessio DA, Fradkin J, et al. Management of hyperglycemia in type 2 diabetes, 2018. A consensus report by the American Diabetes Association (ADA) and the European Association for the Study of Diabetes (EASD). Diabetes Care. 2018;41(12):2669-701. https://doi.org/10.2337/ dci18-0033.

26. Shah AD, Langenberg C, Rapsomaniki E, et al. Type 2 diabetes and incidence of cardiovascular diseases: a cohort study in 1.9 million people. Lancet Diabetes Endocrinol. 2015;3(2):105-13. https://doi. org/10.1016/s2213-8587(14)70219-0.

27. Rungby J, Schou M, Warrer P, Ytte L, Andersen GS. Prevalence of cardiovascular disease and evaluation of standard of care in type 2 diabetes: a nationwide study in primary care. Cardiovasc Endocrinol.
2017;6(4):145-51. https://doi.org/10.1097/xce. 0000000000000135 .

28. MacDonald MR, Petrie MC, Varyani F, et al. Impact of diabetes on outcomes in patients with low and preserved ejection fraction heart failure: an analysis of the candesartan in heart failure: assessment of reduction in mortality and morbidity (CHARM) programme. Eur Heart J. 2008;29(11):1377-85. https://doi.org/10.1093/eurheartj/ehn153.

29. Mamas MA, Sperrin M, Watson MC, et al. Do patients have worse outcomes in heart failure than in cancer? A primary care-based cohort study with 10-year follow-up in Scotland. Eur J Heart Fail. 2017;19(9):1095-104. https://doi.org/10.1002/ejhf. 822 .

30. Go AS, Mozaffarian D, Roger VL, et al. Heart disease and stroke statistics-2014 update: a report from the American Heart Association. Circulation. 2014;129(3):e28-292. https://doi.org/10.1161/01. cir.0000441139.02102.80.

31. Solomon SD, Dobson J, Pocock S, et al. Influence of nonfatal hospitalization for heart failure on subsequent mortality in patients with chronic heart failure. Circulation. 2007;116(13):1482-7. https:// doi.org/10.1161/circulationaha.107.696906.

32. Nanayakkara S, Patel HC, Kaye DM. Hospitalisation in patients with heart failure with preserved ejection fraction. Clin Med Insights Cardiol. 2018;12:1179546817751609. https://doi.org/10. $1177 / 1179546817751609$.

33. Carson PE, Anand IS, Win S, et al. The hospitalization burden and post-hospitalization mortality risk in heart failure with preserved ejection fraction: results from the I-PRESERVE trial (Irbesartan in Heart Failure and Preserved Ejection Fraction). JACC Heart Fail. 2015;3(6):429-41. https://doi.org/ 10.1016/j.jchf.2014.12.017.

34. Lin AH, Chin JC, Sicignano NM, Evans AM. Repeat hospitalizations predict mortality in patients with heart failure. Milit Med. 2017;182(9):e1932-7. https://doi.org/10.7205/milmed-d-17-00017.

35. Braunschweig F, Cowie MR, Auricchio A. What are the costs of heart failure? Europace. 2011;13(Suppl 2):ii13-7. https://doi.org/10.1093/europace/eur081.

36. Bailey RA, Wang Y, Zhu V, Rupnow MF. Chronic kidney disease in US adults with type 2 diabetes: an updated national estimate of prevalence based on Kidney Disease: Improving Global Outcomes (KDIGO) staging. BMC Res Notes. 2014;7:415. https://doi.org/10.1186/1756-0500-7-415.

37. de Boer IH, Rue TC, Hall YN, Heagerty PJ, Weiss NS, Himmelfarb J. Temporal trends in the prevalence of 
diabetic kidney disease in the United States. JAMA. 2011;305(24):2532-9. https://doi.org/10.1001/ jama.2011.861.

38. Levey AS, Eckardt KU, Tsukamoto Y, et al. Definition and classification of chronic kidney disease: a position statement from Kidney Disease: Improving Global Outcomes (KDIGO). Kidney Int. 2005;67(6):2089-100. https://doi.org/10.1111/j. 1523-1755.2005.00365.x.

39. Afkarian M, Sachs MC, Kestenbaum B, et al. Kidney disease and increased mortality risk in type 2 diabetes. J Am Soc Nephrol. 2013;24(2):302-8. https:// doi.org/10.1681/asn.2012070718.

40. Cho NH, Shaw JE, Karuranga S, et al. IDF diabetes atlas: global estimates of diabetes prevalence for 2017 and projections for 2045. Diabetes Res Clin Pract. 2018;138:271-81. https://doi.org/10.1016/j. diabres.2018.02.023.

41. Nguyen NTQ, Cockwell P, Maxwell AP, Griffin M, O’Brien T, O'Neill C. Chronic kidney disease, health-related quality of life and their associated economic burden among a nationally representative sample of community dwelling adults in England. PloS One. 2018;13(11):e0207960. https://doi. org/10.1371/journal.pone.0207960.

42. Gaede P, Vedel P, Parving HH, Pedersen O. Intensified multifactorial intervention in patients with type 2 diabetes mellitus and microalbuminuria: the Steno type 2 randomised study. Lancet. 1999;353(9153):617-22. https://doi.org/10.1016/ s0140-6736(98)07368-1.

43. Ronco C. Cardiorenal syndromes: definition and classification. Contrib Nephrol. 2010;164:33-8. https://doi.org/10.1159/000313718.

44. Inzucchi SE, Zinman B, Wanner C, et al. SGLT-2 inhibitors and cardiovascular risk: proposed pathways and review of ongoing outcome trials. Diabetes Vasc Dis Res. 2015;12(2):90-100. https://doi. org/10.1177/1479164114559852.

45. Perkovic V, Jardine MJ, Neal B, et al. Canagliflozin and renal outcomes in type 2 diabetes and nephropathy. N Engl J Med. 2019;380(24):2295-306. https://doi.org/10.1056/ nejmoa1811744.

46. Cannon CP, McGuire DK, Pratley R, et al. Design and baseline characteristics of the eValuation of ERTugliflozin effIcacy and Safety CardioVascular outcomes trial (VERTIS-CV). Am Heart J. 2018;206:11-23. https://doi.org/10.1016/j.ahj. 2018.08.016.

47. Einarson TR, Acs A, Ludwig C, Panton UH. Prevalence of cardiovascular disease in type 2 diabetes: a systematic literature review of scientific evidence from across the world in 2007-2017. Cardiovasc Diabetol. 2018;17(1):83. https://doi.org/10.1186/ s12933-018-0728-6.

48. Mosenzon O, Wiviott SD, Cahn A, et al. Effects of dapagliflozin on development and progression of kidney disease in patients with type 2 diabetes: an analysis from the DECLARE-TIMI 58 randomised trial. Lancet Diabetes Endocrinol. 2019;7(8):606-17.

49. Norhammar A, Bodegard J, Nystrom T, Thuresson M, Nathanson D, Eriksson JW. Dapagliflozin and cardiovascular mortality and disease outcomes in a population with type 2 diabetes similar to that of the DECLARE-TIMI 58 trial: a nationwide observational study. Diabetes Obes Metab. 2019;21(5):1136-45. https://doi.org/10.1111/dom.13627.

50. Zelniker TA, Wiviott SD, Raz I, et al. SGLT2 inhibitors for primary and secondary prevention of cardiovascular and renal outcomes in type 2 diabetes: a systematic review and meta-analysis of cardiovascular outcome trials. Lancet. 2019;393(10166):31-9. https://doi.org/10.1016/ s0140-6736(18)32590-x.

51. Staels B. Cardiovascular protection by sodium glucose cotransporter 2 inhibitors: potential mechanisms. Am J Cardiol. 2017;120(1s):S28-36. https:// doi.org/10.1016/j.amjcard.2017.05.013.

52. Alicic RZ, Rooney MT, Tuttle KR. Diabetic kidney disease: challenges, progress, and possibilities. Clin J Am Soc Nephrol. 2017;12(12):2032-45. https:// doi.org/10.2215/cjn.11491116.

53. Rahman W, Solinsky PJ, Munir KM, Lamos EM. Pharmacoeconomic evaluation of sodium-glucose transporter-2 (SGLT2) inhibitors for the treatment of type 2 diabetes. Expert Opin Pharmacother. 2019;20(2):151-61. https://doi.org/10.1080/ 14656566.2018 .1543408 .

54. Nguyen E, Coleman CI, Nair S, Weeda ER. Costutility of empagliflozin in patients with type 2 diabetes at high cardiovascular risk. J Diabetes Complicat. 2018;32(2):210-5. https://doi.org/10. 1016/j.jdiacomp.2017.10.006.

55. Gourzoulidis G, Tzanetakos C, Ioannidis I, et al. Cost-effectiveness of empagliflozin for the treatment of patients with type 2 diabetes mellitus at increased cardiovascular risk in Greece. Clin Drug Investig. 2018;38(5):417-26. https://doi.org/10. 1007/s40261-018-0620-x.

56. AstraZeneca. Forxiga $5 \mathrm{mg}$ film-coated tablets: SmPC. 2019. https://www.medicines.org.uk/emc/ product/2865/smpc. Accessed 1 July 2019. 
57. Boehringer Ingelheim Limited. Jardiance $10 \mathrm{mg}$ film-coated tablets: SmPC. 2019. https://www. medicines.org.uk/emc/product/5441/smpc. Accessed 1 July 2019.

58. Napp Pharmaceuticals Limited. Invokana $100 \mathrm{mg}$ and $300 \mathrm{mg}$ film-coated tablets: SmPC. 2019. https://www.medicines.org.uk/emc/product/8855/ smpc. Accessed 1 July 2019.

59. Nathan DM, Buse JB, Kahn SE, et al. Rationale and design of the glycemia reduction approaches in diabetes: a comparative effectiveness study (GRADE). Diabetes Care. 2013;36(8):2254-61. https://doi.org/10.2337/dc13-0356.

60. Marso SP, Daniels GH, Brown-Frandsen K, et al. Liraglutide and cardiovascular outcomes in type 2 diabetes. N Engl J Med. 2016;375(4):311-22. https://doi.org/10.1056/nejmoa1603827.

61. Mann JFE, Orsted DD, Brown-Frandsen K, et al. Liraglutide and renal outcomes in type 2 diabetes. N Engl J Med. 2017;377(9):839-48. https://doi.org/ $10.1056 /$ nejmoa1616011.

62. Marso SP, Bain SC, Consoli A, et al. Semaglutide and cardiovascular outcomes in patients with type 2 diabetes. N Engl J Med. 2016;375(19):1834-44. https://doi.org/10.1056/nejmoa1607141.

63. Gerstein HC, Colhoun HM, Dagenais GR, et al. Dulaglutide and cardiovascular outcomes in type 2 diabetes (REWIND): a double-blind, randomised placebo-controlled trial. Lancet. 2019;394(10193): 121-30. https://doi.org/10.1016/s0140-6736(19) 31149-3.

64. Gerstein HC, Colhoun HM, Dagenais GR, et al. Dulaglutide and renal outcomes in type 2 diabetes: an exploratory analysis of the REWIND randomised, placebo-controlled trial. Lancet. 2019;394(10193):131-8. https://doi.org/10.1016/ s0140-6736(19)31150-x.

65. Li D, Wang T, Shen S, Fang Z, Dong Y, Tang H. Urinary tract and genital infections in patients with type 2 diabetes treated with sodium-glucose cotransporter 2 inhibitors: a meta-analysis of randomized controlled trials. Diabetes Obes Metab. 2017;19(3):348-55. https://doi.org/10.1111/dom. 12825.

66. Jabbour S, Seufert J, Scheen A, Bailey CJ, Karup C, Langkilde AM. Dapagliflozin in patients with type 2 diabetes mellitus: a pooled analysis of safety data from phase IIb/III clinical trials. Diabetes Obes Metab. 2018;20(3):620-8. https://doi.org/10.1111/ dom.13124.

67. Zhang XL, Zhu QQ, Chen YH, et al. Cardiovascular safety, long-term noncardiovascular safety, and efficacy of sodium-glucose cotransporter 2 inhibitors in patients with type 2 diabetes mellitus: a systemic review and meta-analysis with trial sequential analysis. J Am Heart Assoc. 2018. https:// doi.org/10.1161/jaha.117.007165.

68. Tang H, Li D, Wang T, Zhai S, Song Y. Effect of sodium-glucose cotransporter 2 inhibitors on diabetic ketoacidosis among patients with type 2 diabetes: a meta-analysis of randomized controlled trials. Diabetes Care. 2016;39(8):e123-4. https:// doi.org/10.2337/dc16-0885.

69. Wilding J, Fernando K, Milne N, et al. SGLT2 Inhibitors in type 2 diabetes management: key evidence and implications for clinical practice. Diabetes Ther. 2018;9(5):1757-73. https://doi.org/10.1007/ s13300-018-0471-8.

70. Tsimihodimos V, Filippatos TD, Elisaf MS. SGLT2 inhibitors and the kidney: effects and mechanisms. Diabetes Metab Syndr. 2018;12(6):1117-23. https:// doi.org/10.1016/j.dsx.2018.06.003.

71. Lahnwong S, Chattipakorn SC, Chattipakorn N. Potential mechanisms responsible for cardioprotective effects of sodium-glucose co-transporter 2 inhibitors. Cardiovasc Diabetol. 2018;17(1):101. https://doi.org/10.1186/s12933-018-0745-5.

72. Rajasekeran H, Lytvyn Y, Cherney DZ. Sodiumglucose cotransporter 2 inhibition and cardiovascular risk reduction in patients with type 2 diabetes: the emerging role of natriuresis. Kidney Int. 2016;89(3):524-6. https://doi.org/10.1016/j.kint. 2015.12.038.

73. Heerspink HJ, Perkins BA, Fitchett DH, Husain M, Cherney DZ. Sodium glucose cotransporter 2 inhibitors in the treatment of diabetes mellitus: cardiovascular and kidney effects, potential mechanisms, and clinical applications. Circulation. 2016;134(10):752-72. https://doi.org/10.1161/ circulationaha.116.021887.

74. AstraZeneca. DAPACARE Programme. https:// azcvrm.co.za/dapa/dapamech/. Accessed 1 July 2019. 